\title{
Characterisation of Eubacterium-like strains isolated from oral infections
}

\author{
JULIA DOWNES, MARK A. MUNSON, DAVID A. SPRATT, EIJA KONONEN*, EVELIINA TARKKA*, \\ HANNELE JOUSIMIES-SOMER* and WILLIAM G. WADE \\ Molecular Microbial Ecology Programme, Guy's, King's and St Thomas' Dental Institute, King's College \\ London, London SE1 9RT, UK and*Anaerobe Reference Unit, National Public Health Institute, 166 \\ Manneheiminte, Helsinki, Finland
}

\begin{abstract}
The genus Eubacterium currently includes a heterogeneous group of gram-positive, nonspore-forming anaerobic bacilli, many of which are slow growing, fastidious and generally unreactive in biochemical tests. As a consequence, cultivation and identification of isolates are difficult and the taxonomy of the group remains indifferent. In this study, 105 isolates from odontogenic infections, infections associated with dental implants or saliva from healthy subjects and provisionally assigned to the genus Eubacterium were subjected to phenotypic and genotypic analysis. Ninety-one of the isolates were identified as belonging to one of 14 previously described species: Atopobium parvulum $(5$ isolates), A. rimae (29), Bulleidia extructa (2), Cryptobacterium curtum (1), Dialister pneumosintes (1), Eubacterium saburreum (2), E. sulci (8), E. yurii subsp. yurii (1), Filifactor alocis (3), Lactobacillus uli (1), Mogibacterium timidum (13), M. vescum (6), Pseudoramibacter alactolyticus (6) and Slackia exigua (13). The remaining 14 isolates did not correspond to existing species. This study confirms the diversity of organisms provisionally assigned to the genus Eubacterium by conventional identification methods. This group of organisms is frequently isolated from oral infections but their role in the aetiology of these conditions has yet to be determined.
\end{abstract}

\section{Introduction}

Gram-positive, non-spore-forming, anaerobic bacilli are frequently isolated from oral infections such as periodontitis [1,2] and dento-alveolar infections [3]. At present, many of these isolates are assigned to the genus Eubacterium, which comprises a heterogeneous collection of species with DNA $\mathrm{G}+\mathrm{C}$ contents ranging from 30 to $55 \mathrm{~mol} \%$ and has largely been defined by default [4]. Because many of these strains are slow growing and generally unreactive in conventional biochemical tests, it has proved difficult to identify them positively. Recent taxonomic studies of this group have led to the proposal of a number of new genera to accommodate species that were originally placed in the genus Eubacterium but are distinct at the genus level from the type species E. limosum. These include Collinsella aerofaciens [5], Mogibacterium timidum

Received 6 Feb. 2001; revised version received 4 May 2001; accepted 5 May 2001.

Corresponding author: Professor W. G. Wade (e-mail: william.wade@kcl.ac.uk).
[6], Pseudoramibacter alactolyticus [7], Slackia exigua and Eggerthella lenta [8]. Novel species have also been proposed either within the genus Eubacterium or in related or novel genera, both in the low $\mathrm{G}+\mathrm{C}$ grampositive and Actinobacteria divisions, such as $E$. minutum [9], Cryptobacterium curtum [10], M. vescum [6] and Bulleidia extructa [11].

The aim of this study was to identify definitively 105 isolates from oral infections, provisionally assigned to the genus Eubacterium, by means of a comprehensive range of phenotypic and genotypic analyses.

\section{Materials and methods}

A total of 105 isolates of anaerobic, gram-positive nonspore-forming rods from the oral cavity, provisionally identified as belonging to the genus Eubacterium [12], were included in the study. Isolates were from odontogenic infections (84 isolates), infections associated with dental implants (13) and saliva from healthy subjects (8) and were isolated at the National Public Health Institute in Helsinki, Finland. 
Isolates were grown at $37^{\circ} \mathrm{C}$ on Fastidious Anaerobe Agar (FAA, LabM) supplemented with horse blood 5\% under anaerobic conditions $\left(\mathrm{N}_{2} 80 \%, \mathrm{H}_{2} \quad 10 \%, \mathrm{CO}_{2}\right.$ $10 \%$ ). Colonial morphologies were determined after incubation for 7 days by means of a plate microscope. Cell morphologies were recorded after Gram's staining of 3-day-old cultures.

Fermentation tests were performed with pre-reduced, anaerobically sterilised (PRAS) sugars according to the methods of Holdeman et al. [12] except that the PRAS media were prepared in an anaerobic workstation with pre-reduced distilled water. Other biochemical tests, including indole production, hydrolysis of aesculin and arginine and growth stimulation by Tween $800.5 \%$ and arginine $0.5 \%$, were performed as described by Holdeman et al. [12] and Summanen et al. [13].

Bacterial isolates were grown in PYG broth and shortchain volatile and non-volatile fatty acids were extracted by standard methods [12] and analysed by gas chromatography with a capillary column coated with CP-Wax 58 solid phase.

Enzyme profiles were generated with the Rapid ID 32A identification system for anaerobes (bioMérieux) according to the manufacturer's instructions except where indicated in the text. Bacteria were harvested from blood agar plates (Blood Agar Base No. 2, LabM, with horse blood $5 \%$ ) incubated anaerobically at $37^{\circ} \mathrm{C}$ for $72 \mathrm{~h}$.

Protein profiles of whole-cell proteins were generated by SDS-PAGE with $10-15 \%$ gradient gels and the PhastSystem (Pharmacia) as described previously [14] except that the cells were pre-treated with lysozyme $50 \mu \mathrm{g} / \mathrm{ml}$ for $2 \mathrm{~h}$ at $37^{\circ} \mathrm{C}$ and vortex mixed for $2 \mathrm{~min}$ before boiling.

DNA was isolated from the bacteria by a method optimised for gram-positive bactera [15]. The 16S rRNA genes were amplified by PCR with primers $27 \mathrm{~F}$ and 1525R [16] in a Uno II Thermocycler (Biometra, Maidstone, Kent) with PCR Buffer (Bioline, London) containing $1.5 \mathrm{mM} \mathrm{MgCl} 2,200 \mu \mathrm{M}$ dNTPs, $1 \mathrm{mM}$ of each oligonucleotide primer, 1 U Taq DNA polymerase (Bioline) and template DNA in a total volume of $100 \mu 1$. Thirty amplification cycles were performed with a denaturing temperature of $94^{\circ} \mathrm{C}$ for $1 \mathrm{~min}$, annealing at $54^{\circ} \mathrm{C}$ for $1 \mathrm{~min}$ and elongation at $72^{\circ} \mathrm{C}$ for 2 min. PCR products were sequenced directly with the $\mathrm{CEQ}^{\mathrm{TM}} 2000$ Dye Terminator Cycle Sequencing Kit (Beckman Coulter) and $60 \mathrm{ng}$ of template DNA, according to the manufacturer's instructions. Sequencing was performed with an automated sequencer $\left(\mathrm{CEQ}^{\mathrm{TM}} 2000\right.$ DNA Analysis System, Beckman Coulter) with primers 27F, 342R, 357F, 519R, 907R, 926F, 1100R, 1114F, 1392R and 1525R [16].

Sequences were connected by using DNASIS (Hitachi) and then submitted to the Ribosomal Database Project II (RDP) [17] via the world-wide web for provisional identification in the Sequence_ Match programme. From the phylogenetic position indicated by Sequence_ Match, related sequences were selected and aligned with the type strains of the species by means of CLUSTAL W [18].

\section{Results and discussion}

The results of the identification process are shown in Table 1 along with differential phenotypic characteristics of the species. The isolates were provisionally grouped on the basis of colony and gram-strain morphologies, fermentation of glucose, end-products of fermentation in PYG broth and enzyme profiles obtained with the Rapid ID 32A identification system. Partial 16S rRNA gene sequence analysis was performed on 72 of the 105 isolates. All isolates of Atopobium parvulum, A. rimae and Lactobacillus uli and all strains of $M$. timidum and $M$. vescum were sequenced as they were difficult to differentiate by phenotypic characteristics. Twenty isolates representative of the remaining 11 groups were sequenced to confirm identifications.

Ninety-one isolates were identified as belonging to one of 14 previously described species. A further 13 isolates constituted a homogeneous group which appeared to represent a novel species. The homogeneity of the group was confirmed by protein profile analysis performed on 9 of the 13 isolates. Phylogenetic analysis of the sequence data obtained for 8 of the 13 isolates assigned this group to the clostridial subphylum within the low $\mathrm{G}+\mathrm{C}$ gram-positive division. The closest match indicated by the Sequence Match programme of the RDP was B. extructa [11] with a S_ab value of 0.74 . Another single isolate (AHS 5884) also appeared to represent an as yet undescribed species. It was most closely related to M. timidum with a S_ab value of 0.66 . Further work is necessary on these 14 unidentified isolates to clarify their phylogenetic position and to fully define their phenotypic characteristics.

Thirty-four isolates were identified as belonging to the genus Atopobium. This genus within the Actinobacteria was created to include the former species Streptococcus parvulus, L. rimae and L. minutus as A. parvulum, $A$. rimae and A. minutum [19]. A. parvulum and $A$. rimae have been isolated from human gingival crevices and periodontal pockets [20]. Since their description, reports of their isolation have been rare, but here they were the most frequent genus found. The species are phenotypically very similar, with growth in PYG broth enhanced by the addition of Tween 80 , and acetate, major amounts of lactate and occasionally trace amounts of succinate produced as end-products of glucose fermentation. Olsen et al. [20] compared the 
sugar fermentation reactions of $A$. parvulum and $A$. rimae. The only significant difference was that all of 82 isolates of A. parvulum fermented lactose whereas only two of 67 isolates of $A$. rimae tested were positive. The present study also found differences in the enzyme profiles obtained with the Rapid ID 32A identification system (Table 1), although the enzyme profiles could be quite variable. One isolate of $L$. uli was found in this study and was identified by 16S rRNA gene sequence analysis. $L$. uli is phenotypically similar to $A$. parvulum and $A$. rimae. Olsen et al. [20] reported that all 48 strains of $L$. uli tested were negative for trehalose fermentation in PRAS media without added serum, whereas all 82 strains of A. parvulum and 66 of 67 strains of A. rimae were positive. Furthermore, these workers isolated $L$. uli from human gingival crevices, especially from patients with periodontitis.

B. extructa is a recently described species of anaerobic gram-positive bacilli that was isolated from human periodontal pockets and a dento-alveolar abscess [3]. Analysis of 16S rRNA gene sequences of the isolates showed that they constituted a novel branch of the low $\mathrm{G}+\mathrm{C}$ gram-positive division of the phylogenetic tree most closely related to Holdemania filiformis and Erysipelothrix rhusiopathiae. The two isolates identified in this study had the same phenotypic characteristics and protein profiles as the four strains described previously [11], with growth in broth enhanced by the addition of fermentable sugars and Tween 80 , and with acetate, lactate and trace amounts of succinate as endproducts of fermentation. The Rapid ID 32A enzyme profile along with protein profiles distinguished $B$. extructa from other species with similar phenotypic characteristics.

C. curtum is another recently described gram-positive anaerobic rod isolated from a periodontal pocket of an adult patient with periodontal disease and from a necrotic dental pulp [10]. The organism is asaccharolytic and unreactive in most of the conventional biochemical tests. No short-chain fatty acids are detected as end-products of glucose metabolism. In this study, the single isolate of C. curtum was from a patient with an odontogenic infection. Moore [21] summarised findings from a number of studies investigating the predominant microflora in periodontitis and identified several novel Eubacterium taxa. One of these groups, Eubacterium D40, is phenotypically identical to $C$. curtum. We have examined six strains of D40 and found them to have similar characteristics to the two strains studied by Nakazawa et al. [10] and to share $>98 \%$ 16S rRNA gene sequence similarity with the type strain of C. curtum (unpublished data). Furthermore, we found that growth in PYG broth could be enhanced by arginine $0.5 \%$ and there was no growth in bile $20 \%$. In the Rapid ID $32 \mathrm{~A}$ identification system, the isolate identified in this study and the six D40 strains were all positive for arginine dihydrolase and arginine arylamidase, six of the seven 
strains were positive for leucine arylamidase, five were positive for glycine arylamidase and one was positive for leucyl glycine arylamidase.

The species Fusobacterium sulci and F. alocis have recently been re-named as E. sulci and Filifactor alocis on the basis of 16S rRNA gene sequence analysis which showed that neither species belonged to the genus Fusobacterium [22]. Both these species were found to be more prevalent in the subgingival flora than in the supragingival flora and in diseased than in healthy sites [23]. The three isolates of F. alocis in this study and five isolates of $E$. sulci were recovered from odontogenic infections. One E. sulci isolate was from a patient with peri-implantitis and two were from saliva of healthy subjects. Both species could be distinguished from each other and other species in this study by their enzyme profiles and end-products of fermentation in PYG broth (Table 1).

The genus Mogibacterium was recently proposed to include E. timidum and two novel species, M. vescum and M. pumilum, all of which have been isolated from human periodontal pockets [6]. Thirteen isolates from this study were identified as M. timidum, 11 of which were isolated from odontogenic infections and two from peri-implantitis. $16 \mathrm{~S}$ rRNA gene sequence analysis of a further six strains revealed that they had sequence similarity values over 454 unambiguously aligned bases ranging from $95.2 \%$ to $95.6 \%$ when compared to the type strain of $M$. timidum, but $99.3-99.6 \%$ sequence similarity with the $M$. vescum type strain, and hence were identified as $M$. vescum. Biochemically, there is little to distinguish between $M$. timidum and $M$. vescum as both are asaccharolytic, unreactive in conventional tests and produce phenyl acetate as an end-product of fermentation in PYG broth. In this study, all 19 isolates of Mogibacterium gave a positive reaction for the enzyme proline arylamidase only in the Rapid ID 32A identification system when it was incubated in an aerobic atmosphere, as recommended by the manufacturer. However, if incubated under anaerobic conditions, in addition to the proline arylamidase activity the 13 isolates of $M$. timidum also showed pyroglutamate arylamidase activity, whereas the 6 isolates of $M$. vescum did not. Protein profiles were also performed on 5 of the 13 isolates of M. timidum and the 6 isolates of $M$. vescum in this study. As previously reported [6], both species could be differentiated on whole-cell protein profiles. Differences in colony morphology were also observed by plate microscopy after incubation for 7 days on FAA; $M$. timidum colonies were circular, entire, convex and translucent with colony diameters of $0.3-0.5 \mathrm{~mm}$, compared with $M$. vescum colonies which were circular, entire, umbonate with an opaque, off-white centre and colony diameters of $0.6-0.8 \mathrm{~mm}$.

\section{E. alactolyticum was reclassified as Pseudoramibacter}

alactolyticus following 16S rRNA gene sequence analysis which showed only $91 \%$ sequence similarity between the type strains of E. alactolyticum and E. limosum, the type species for the genus Eubacterium [7]. P. alactolyticus has been isolated from root canals and from dental calculus and gingival crevices of patients with periodontal disease [4]. The six isolates in this study were from odontogenic infections. $P$. alactolyticus can be distinguished from Eubacterium and other Eubacterium-like species by the lack of enzymic activity in the Rapid ID 32A system and the formation of caproic acid as an end-product of fermentation in PYG broth (Table 1).

The genus Slackia was recently proposed to include the former E. exiguum and Peptostreptococcus heliotrinreducens as $S$. exigua and $S$. heliotrinireducens, with $94.7 \%$ 16S rRNA gene sequence similarity between the type strains of the two species [24]. Phylogenetic analysis placed both species within the family Coriobacteriaceae in the Actinobacteria (high $\mathrm{G}+\mathrm{C}$ ) division with the $\mathrm{G}+\mathrm{C}$ content of their DNA ranging from 60 to $64 \mathrm{~mol} \%$. S. exigua has been isolated from human necrotic pulp samples, periapical infections and acute dento-alveolar abscesses [24]. The 13 isolates of $S$. exigua in this study were all from odontogenic infections. Protein profiles performed on 5 of the 13 strains confirmed the homogeneity of the group.

Two isolates of E. saburreum and one of E. yurii subsp. yurii were identified in this study. Both species are indole positive but could be differentiated in this study by aesculin hydrolysis and enzyme profiles (Table 1). The type strain of E. saburreum does not produce urease [4], whereas the two strains in this study were urease positive in the Rapid ID 32A system. Protein profiles performed on the two isolates also showed some differences when compared with the type strain of E. saburreum. Margaret and Krywolap [25] isolated E. yurii from periodontal pockets and found that it made up c. $1 \%$ of the cultivable flora of their subgingival plaque samples. Despite this, the isolation of E. yurii is rarely reported in the literature. Interestingly, they also reported that E. yurii produced propionate as an end-product of fermentation. The isolate studied here did not produce propionate despite good growth in PYG broth.

It was perhaps suprising that one isolate in this study was identified as Dialister pneumosintes, a gramnegative bacillus. However, Eubacterium cells may decolorise readily in Gram's staining and appear gramvariable or gram-negative [4]. D. pneumosintes also resembles some Eubacterium spp. in its morphology and lack of activity in conventional biochemical tests [26]. This has been noted previously in respect of strain SC3D which was originally identified as Eubacterium by conventional tests but was found by $16 \mathrm{~S}$ rRNA gene sequence analysis to belong to $D$. pneumosintes (Nucleotide accession no. Z36297). 
This study has emphasised the heterogeneity of the genus Eubacterium, with 10 genera being identified from a collection of 105 isolates provisionally assigned to the genus Eubacterium. Members of this genus have hitherto been identified as Eubacterium by default because they have failed to produce the major metabolic end-products that would have placed them within one of the other genera of gram-positive, non-sporeforming, anaerobic bacilli. However, as a result of the use of recently introduced techniques such as $16 \mathrm{~S}$ rRNA gene sequencing, many new genera have been proposed to accommodate both novel species and former Eubacterium spp. that have been shown to be phylogenetically distinct from the type species $E$. limosum. The clinical importance of Eubacterium in oral infections is yet to be established. In the studies that supplied the isolates for this investigation, isolates provisionally identified as Eubacterium were isolated from $39 \%$ of the pus or tissue samples collected from odontogenic infections, consisting mostly of periapical abscesses with some cases of pericoronitis and infected sockets post-extraction, and in $65 \%$ of cases with periimplantitis. In all cases, these organisms were found as a part of mixed oral microflora. The frequent isolation of species of this group from such infections indicates that they could play an important role. The recent and continuing improvements in the taxonomy of this group will allow consistent identification in different laboratories and greatly aid the elucidation of their precise role in disease.

This study was supported by a grant from the Wellcome Trust (ref. 058950).

\section{References}

1. Moore WEC, Holdeman LV, Cato EP, Smibert RM, Burmeister JA, Ranney RR. Bacteriology of moderate (chronic) periodontitis in mature adult humans. Infect Immun 1983; 42: 510-515.

2. Moore WEC, Holdeman LV, Smibert RM, Hash DE, Burmeister JA, Ranney RR. Bacteriology of severe periodontitis in young adult humans. Infect Immun 1982; 38: 1137-1148.

3. Wade WG. The role of Eubacterium species in periodontal disease and other oral infections. Microb Ecol Health Dis 1997; 9: 367-370.

4. Moore WEC, Holdeman Moore LV. Genus Eubacterium Prévot 1938. In: Sneath PHA, Mair NS, Sharpe MS, Holt JG (eds) Bergey's manual of systematic bacteriology, vol 2. Baltimore, MD, Williams and Wilkins. 1986: 1353-1373.

5. Kageyama A, Benno Y, Nakase T. Phylogenetic and phenotypic evidence for the transfer of Eubacterium aerofaciens to the genus Collinsella as Collinsella aerofaciens gen. nov., comb. nov. Int J Syst Bacteriol 1999; 49: 557-565.

6. Nakazawa F, Sato M, Poco SE et al. Description of Mogibacterium pumilum gen. nov., sp. nov. and Mogibacterium vescum gen. nov., sp. nov., and reclassification of Eubacterium timidum (Holdeman et al. 1980) as Mogibacterium timidum gen. nov., comb. nov. Int J Syst Evol Microbiol 2000; 50: 679-688.

7. Willems A, Collins MD. Phylogenetic relationships of the genera Acetobacterium and Eubacterium sensu stricto and reclassification of Eubacterium alactolyticum as Pseudorami- bacter alactolyticus gen. nov., comb. nov. Int J Syst Bacteriol 1996; 46: 1083-1087.

8. Wade WG, Downes J, Dymock D et al. The family Coriobacteriaceae: reclassification of Eubacterium exiguum (Poco et al. 1996) and Peptostreptococcus heliotrinreducens (Lanigan 1976) as Slackia exigua gen. nov., comb. nov. and Slackia heliotrinireducens gen. nov., comb. nov., and Eubacterium lentum (Prevot 1938) as Eggerthella lenta gen. nov., comb. nov. Int J Syst Bacteriol 1999; 49: 595-600.

9. Poco SE, Nakazawa F, Sato M, Hoshino E. Eubacterium minutum sp. nov., isolated from human periodontal pockets. Int J Syst Bacteriol 1996; 46: 31-34.

10. Nakazawa F, Poco SE, Ikeda T et al. Cryptobacterium curtum gen. nov., sp. nov., a new genus of gram-positive anaerobic rod isolated from human oral cavities. Int $J$ Syst Bacteriol 1999; 49: 1193-1200.

11. Downes J, Olsvik B, Hiom SJ et al. Bulleidia extructa gen. nov., sp. nov., isolated from the oral cavity. Int $J$ Syst Evol Microbiol 2000; 50: 979-983.

12. Holdeman LVH, Moore WEC, Cato EP. Anaerobe laboratory manual, 4th edn. Blacksburg, VA, Virginia Polytechnic Institute and State University. 1977.

13. Summanen P, Baron EJ, Citron DM et al. Wadsworth anaerobic bacteriology manual, 5th edn. Belmont, CA, Star Publishing. 1993.

14. Slayne MA, Aldred MJ, Wade WG. A rapid, semi-automated SDS-PAGE identification system for oral anaerobic bacteria. $J$ Appl Bacteriol 1990; 68: 391-395.

15. Grimont F, Grimont PAD. DNA fingerprinting. In: Stackebrandt E, Goodfellow M (eds) Nucleic acid techniques in bacterial systematics. Chichester, John Wiley \& Sons. 1991: 249-279.

16. Lane DJ. 16S/23S rRNA sequencing. In: Stackebrandt E, Goodfellow M (eds) Nucleic acid techniques in bacterial systematics. Chichester, John Wiley \& Sons. 1991: 115-175.

17. Maidak BL, Cole JR, Lilburn TG et al. The RDP (Ribosomal Database Project) continues. Nucleic Acids Res 2000; 28: $173-174$.

18. Thompson JD, Higgins DG, Gibson TJ. CLUSTAL W: improving the sensitivity of progressive multiple sequence alignment through sequence weighting, position-specific gap penalties and weight matrix choice. Nucleic Acids Res 1994; 22: $4673-4680$.

19. Collins MD, Wallbanks S. Comparative sequence analyses of the 16S rRNA genes of Lactobacillus minutus, Lactobacilllus rimae and Streptococcus parvulus: proposal for the creation of a new genus Atopobium. FEMS Microbiol Lett 1992; 95: 235-240.

20. Olsen I, Johnson JL, Moore LVH, Moore WEC. Lactobacillus uli sp. nov. and Lactobacillus rimae sp. nov. from the human gingival crevice and emended descriptions of Lactobacillus minutus and Streptococcus parvulus. Int J Syst Bacteriol 1991; 41: 261-266.

21. Moore WEC. Microbiology of periodontal disease. J Periodontal Res 1987; 22: 335-341.

22. Jalava J, Eerola E. Phylogenetic analysis of Fusobacterium alocis and Fusobacterium sulci based on 16S rRNA gene sequences: proposal of Filifactor alocis (Cato, Moore and Moore) comb. nov. and Eubacterium sulci (Cato, Moore and Moore) comb. nov. Int J Syst Bacteriol 1999; 49: 1375-1379.

23. Cato EP, Moore LVH, Moore WEC. Fusobacterium alocis sp. nov. and Fusobacterium sulci sp. nov. from the human gingival sulcus. Int J Syst Bacteriol 1985; 35: 475-477.

24. Poco SE, Nakazawa F, Ikeda T, Sato M, Sato T, Hoshino E. Eubacterium exiguum sp. nov., isolated from human oral lesions. Int J Syst Bacteriol 1996; 46: 1120-1124.

25. Margaret BS, Krywolap GN. Eubacterium yurii subsp. yuri sp. nov. and Eubacterium yurii subsp. margaretiae subsp. nov.: test tube brush bacteria from subgingival dental plaque. Int J Syst Bacteriol 1986; 36: 145-149.

26. Moore LVH, Moore WEC. Oribaculum catoniae gen. nov., sp. nov.; Catonella morbi gen. nov., sp. nov.; Hallella seregens gen. nov., sp. nov.; Johnsonella ignava gen. nov., sp. nov.; and Dialister pneumosintes gen. nov., comb. nov., nom. rev., anaerobic gram-negative bacilli from the human gingival crevice. Int J Syst Bacteriol 1994; 44: 187-192. 